sometimes he would fall. About two months after this the arm began to exhibit movements very similar to those at present existing, but in a less degree. He could not use it to take any food. It has not been getting any worse for some jears. Family history very good.

Galvanism was thetreatment pursued, and the continuous current was used constantly for three months every second day, but failed to produce any beneficial effect; the patient was therefore dismissed after three months of treatment. After this, numerous other remedies, including arsenic and most of the mineral tonics, phosphorus, \&c., were carefully tried by Dr. Forrest, but with equally little advantage. 'The patient was in the course of the next year or so lost sight of, and the only thing afterwards that could be heard of him was that the whole family had suddenly taken their departure for America, without leaving any indication of their destination, or keeping up any correspondence, so far as could be ascertained, with Glaggow.

To these cases $I$ think it right to add a brief account of one other, not as a well-characterised case of athetosis simply, but as illustrating its possible connexion with the same classes of cerebral lesions as, under other circumstances, may develop hemiplegia or hemispasm of a less unusual kind. This case is at present under the care of Dr. Finlayson, in the Western Infirmary, and was regarded by him at various periods since November, 1875 , as a case of hemiplegia, with "late rigidity," and at one time slight paralysis of the facial muscles on the same side as the paralysis of the limbs. There is nothing in the history of the case from this point of view to demand detailed notice, except the occurrence of frontal headaches for some months as a precursor of the paralytic symptoms. These were at first and throughout without any kind of sudden seizure or unconsciousness; there were simply inversion and dragging of the left foot in walking, and diminished power in the lef $t$ hand, especially in the thumb. The statement of the mother was to the effect that there was no pain in the limbs, nor any twitchings or convulsions in the earlier stages of the case. This impression is corroborated generally by Dr. Finlayson's recollection of the time at which the patient, a girl now of nearly nine years old, first came under his observation. It is to be remarked that Dr. Finlayson's acquaintance with both the cases of athetosis above recorded, and his very careful and repeated study in detail of the one occurring in 1872 , give to his impressions as to the previous state of his present patient a special importance in connexion with this subject. Rigidity seems to have been a late phenomenon, and is first distinctly noted in a report dated September, 1876. This patient was readmitted on April 14th, 1877, and is now under observation under the most favourable circumstances for comparison with the case first in order in the present communication.

The following are the most recent notes of the case of Elizabeth L_—, the girl above referred to.-April 14th, 1877: Patient was again admitted to-day, the mother thinking that she is worse at walking. The previous notes describe her condition pretty accurately. She has no headache nor sickness, and was attending school up to the date of her admission. She still walks upon the toes of her left foot, the beel being drawn up by the action of the muscles of the calf; when she makes an effort, however, she can bring the heel to the ground. When lying in bed the foot is extended, and so firmly that little motion can be communicated to it. The contraction of the flexors of the left arm still continues, so that the hand is flexed, and the fingers, especially the thumb, are drawn into the palm; she is able to extend the fingers, however, but only when the hand is flexed; and if the hand be over. extended the fingers are flexed. She is unable to retain the arm in a supine position, for when it is so placed it is immediately drawn back by the pronators. Perhaps on account of the presence in Dr. Gairdner's ward of a little girl affected with athetosis, some special attention is directed to an element in this case which may have formerly been overlooked-namely, the presence of a certain amount of spasm in addition to the mere contraction and rigidity of the muscles, this spasm occurring at times quite apart from the will or even against it, as when she tries to keep her arm by her side in bed, the forearm sometimes rises up, and the hand becomes flexed at the wrist and the fingers extended, evidently in opposition to her will; at other times, when she attempts to perform certain movements desired, there seems to be an element of uncontrollable spasm, associated with complex movements, by which she has to carry out simple processes. These involuntary spasmodic movements, however, are but slight as compared either with the case at present in Dr. Gairdner's ward, or with the one described by him a few years ago. In reference to the note made above as to the difficulty of keeping the hand in the supine position, it would seem as if this difficulty varied; so that at times she is able to keep it in the position from which at other times it is quickly twitched away. There is still a slight irregularity in the heart's action, and in the region of the apex there is a very slight murmur, or at least prolongation of the first. There is no distinct deviation of the tongue to either side, and the sight remains good.

In addition to these records of personal experience, I will here subjoin a few brief notes kindly furnished by $\mathrm{Dr}$. Charteris of the case alluded to above, and which, from having once seen the patient, I have no difficulty in recognising as a case of athetosis.

H. C-, aged six years, was admitted into the Glasgow Royal Infirmary on the 23rd of January last. My assistant, Mr. Davis, told me that it was a curious case, being neither hemiplegia nor chorea, and that the history was also peculiar. It appeared from the mother's statement that two years ago the child was observed to kalt, and this was at first ascribed to her attempting to imitate the walking of a little girl companion who had had her foot amputated in the infirmary. It was noted, however, that the movements were not imitative, for after the lapse of three months she was unable to stand. Three months later, or six months from the first symptoms, the hand was seen to be implicated, and though she was able to grasp anything offered to her. yet she, curiously, could not let it go. The fingers were kept firmly flexed with the tips in the palm of the hand, and when she wished to make them straight she required to use her right hand to do so. The leg gradually improved as the hand became worse.

On her admission into the infirmary it was observed that the left hand was in a state of extreme pronation, and everted, with the index-finger drawn across the palm to the little finger of the same hand. When told to put out her hand, she lifted up her shoulders, and brought the arm round with a leisurely circular, not jerking sweep, and tinus accomplished the desire to place it in mine. In walking, the movements of the left foot are slightly im. peded, as if the foot was too heavy for her. There is a difference in girth between the right and left arm, the left being less than the right by about five-eightbs of an inch immediately below the insertion of the deltoid, and above the wrist by about one-eighth of an inch. The mother appears a healthy woman, and has had a family of eight children, all of whom are alive, and the child, she said, was the only one that ever ailed anything. The child remained in the hospital for six weeks, and had the constant current employed on alternate days. She also was ordered a bromide of potass mixture. On her leaving there was not much if any improvement.

(To be concluded.)

\section{OBSERVATIONS ON THE USE OF CHLORAL.}

BY Dr. OSCAR LIEBRETCH,

PROFHSSOR OF THERAPEUTICS, UNIVRBSTYX OF BHREIT

IN consequence of the great interest which has been shown in the medicinal use of chloral, I beg to submit the following remarks :-

The recent death of Mr. F. M. Levison has, not unjustly, excited commotion in the medical world, and will give me an opportunity of communicating the view at which I have arrived from my own experience.

The normal dose of chloral hydrate in a case of simple insomnia should not exceed 1.25 to 2 grammes $(19 \cdot 3$ to 30.8 grains). It is, however, of course, necessary to individualise. It will generally be observed, that persons who can take large quantities of alcohol in any form, or who are accustomed to its use, require a considerably larger dose; while for enfeebled and exhausted individuals, unaccustomed to alcohol, a smaller dose is sufficient. From my exper ' $e$, 
I can assert that, even when chloral hydrate has been used for a year, the dose-provided that the patient's condition remain the same-does not require to be increased. Before entering on a more detailed statement of these facts, I will give a short sketch of what has come under my notice in Dr. Levinstein's Maison de Santé:-

MALE DEPARTMENT.

\begin{tabular}{|c|c|c|c|c|}
\hline Name. & $\begin{array}{l}\text { Duration } \\
\text { in Months. }\end{array}$ & Dose. & Result. & $\begin{array}{l}\text { General } \\
\text { Condition. }\end{array}$ \\
\hline $\mathrm{Mr}, \mathrm{K}-\mathrm{h}, \ldots \ldots \ldots \ldots$ & $4 \frac{1}{2}$ & $\begin{array}{c}\text { Grammes. } \\
3\end{array}$ & $\left\{\begin{array}{c}\text { Discharged } \\
\text { relatively }\end{array}\right\}$ & Good \\
\hline $\begin{array}{l}\text { Merchant B.......... } \\
\text { Merchant M.......... }\end{array}$ & $\begin{array}{l}5 \\
6 \frac{1}{2}\end{array}$ & $\begin{array}{l}3 \\
3\end{array}$ & $\begin{array}{l}\text { Do. } \\
\text { Do. }\end{array}$ & $\begin{array}{l}\text { Do. } \\
\text { Do. }\end{array}$ \\
\hline Dr. A................... & 10 & 3 & $\left\{\begin{array}{c}\text { Still in the } \\
\text { institution }\end{array}\right\}$ & Do. \\
\hline Merchant H......... & 6 & 3 & $\left\{\begin{array}{c}\text { Discharged } \\
\text { improved }\end{array}\right\}$ & $\begin{array}{c}\text { Paralysig of } \\
\text { the insane }\end{array}$ \\
\hline Mr. R. ........ & 5 & 4 & $\left\{\begin{array}{c}\text { Discharged } \\
\text { cured }\end{array}\right\}$ & Good \\
\hline Mr.P........ & $5 \frac{x}{2}$ & 4 & $\left\{\begin{array}{c}\text { Discharged } \\
\text { improved }\end{array}\right\}$ & Do. \\
\hline$M r . K \rightarrow 0$. & 8 & 3 & $\left\{\begin{array}{c}\text { Still in the } \\
\text { institution }\end{array}\right\}$ & Do. \\
\hline
\end{tabular}

FEMALE DEPARTMENT.

\begin{tabular}{|c|c|c|c|c|}
\hline Name. & $\begin{array}{l}\text { Duration } \\
\text { in Months. }\end{array}$ & Dose. & Result. & $\begin{array}{c}\text { General } \\
\text { Condition. }\end{array}$ \\
\hline Mirs. S. ................ & 32 & $\underset{4}{\text { Grammes. }}$ & $\left\{\begin{array}{c}\text { Still in the } \\
\text { institution }\end{array}\right\}$ & Good \\
\hline Mrs. L. ................ & 24 & 3 & Do. & Do; \\
\hline Miss W................. & 36 & 4 & Do. & $\left\{\begin{array}{c}\text { Pulmonary } \\
\text { phthisis }\end{array}\right.$ \\
\hline Mrs. C. ................. & 10 & 4 & Do. & Good \\
\hline Mrs. B. ................. & 5 & 4 & $\left\{\begin{array}{c}\text { Discharged } \\
\text { cured }\end{array}\right\}$ & Do. \\
\hline Mrs. G. ......... & 8 & 4 & $\left\{\begin{array}{c}\text { Still in the } \\
\text { institution }\end{array}\right\}$ & Do. \\
\hline
\end{tabular}

Chloral hydrate differs essentially from opium and its alkaloids, of which it may be asserted with certainty that, in order to produce the same effect on the organism during their continued use, the dose must be increased to an incredible amount. At the same time every observant physician will arrive at the conclusion that a patient never acquires the same tolerance of chloral hydrate as is characteristic of the use of opium and its alkaloids. A patient is not reminded of opium and morphia by want of sleep, but by a peculiar sensation which has been designated by the fairly appropriate name of "morphia-hunger"; it is not unlike the condition in which a smoker finds himself when longing for tobacco.

The amount of the dose for continued use varies according to the pathological cunditions. For some persons one gramme is enough, others are only content with three grammes. The sudden production of dangerous symptoms by a normal dose after chloral has been used for some time, has not been observed by me; and the statement as yet rests on no well authenticated cases. I have already referred to this in $\mathrm{my}$ Treatise on Chloral Hydrate (third edition, Berlin), remarking that Crichton Browne's case (THe LanceT, 1871, vol. i., p. 440) cannot be adduced as an instance of the injurious action of chloral. The patient, who was the subject of melancholia, took, for ten months, two-gramme doses of chloral, and then sudden death occurred after a dose of two grammes. How of ten does not sudden death occur in the insane without the cause being known? That death should occur suddenly after a single dose of two or three grammes may be explained by a fact which does not place the conacientiousness of the vendor in a very pleasant light. Before its introduction into practice, chloral was known to most chemists by name only, so that preparations were brought into the market which not only contained little chloral, but were loaded with noxious ingredients. I can here relate some facts showing how chloral hydrate com. pletely fell into disuse in certain districts. In Bavaria, a patient of Dr. Siegmund, a Berlin physician, used no chloral, although suffering from severe insomnia, because it always made him ill; and he heard the same complaint from other persons. Dr. Siegmund repeated the experiment with another preparation of chloral, which at once produced the desired result; and from that time the patient has used this chloral without perceiving any bad result.
With such impure preparations it is impossible for the physician to learn the dose.

A case interesting in this respect has been described by a Bavarian physician, Dr. Mayer, in the Correspondenzblatt der deutschen Gesellschaft für Psychiatrie und gerichtliche Psychologie. A physician was obliged to administer to a female patient, on account of insomnia, six or seven grammes of chloral. After the administration of one of these doses, the physician was called to the patient, who was in a very deep sleep, which lasted forty hours. On inquiry, he found that the otherwise not very conscientious apothecary had brought a new preparation into use. In this case, the first preparation was fortunately only deficient in chloral, without containing injurious substances. Other cases, however, may be related which cause suspicion.

In a hospital here chloral hydrate was used, and the physician came to $m e$ in a state of perplexity to describe the peculiar effect of the chloral. The patients did not obtain rest, but became delirious; their faces assumed a very red appearance, and their conjunctivæ were evidently in. jected. I had the chloral hydrate given to me, and now use it in demonstrating to $m y$ pupils the impurities, consisting of various products containing chlorine.

It is in America especially that a bad chloral hydrate is constantly supplied, and $I$ am, therefore, not surprised that a dose of twenty grains should have produced a fatal result in a case reported there. Dr. E. F. Ingals relates, in the Chicago Medical Journal and Examiner, a case which Dr. Aschbough had seen in a friend's practice. This case is incapable of being easily analysed, as an exact description is not given, and I agree with the opinion expressed by the Medical Examiner, that a case of this kind ought to be described clearly. Already before this, I believe, I was able to assert that a chloral or a commercial solution was in use regarding which it was impossible to learn what material was employed in ita manufacture.

From the first it has been my endeavour to furnish the manufacturers of chloral with complete details, so as to keep up a good preparation, and I have especially pointed out that the chloral hydrate in cakes must be purified from benzol by several crystallisations. There are then left dry crystals, in the place of cakes which contain a mass of impurities. These crystals can be kept for any time; they do not undergo decomposition, and are free from every impurity. As this operation is attended with greater labour, there is a slight increase in the price per pound. The result of this small increase of price, however, is that the medicine is in the greatest danger as regards its employment, and the benefit which might be derived from it is almost entirely lost. As has already been observed, in nearly all America cakes are alone used, which, although perhaps good at first, are readily decomposed. Of the lozenges which are sold it is often alleged that they are made from the crystals. These have a bad effect, while the testing of chloral in solution cannot be carried out, since, in determining the chloral, the impurities undergo further decom. position.

As regards the dose, it is not possible to speak of a normal dose. I have already pointed out that ordinarily small doses aggravate the condition in trismus and tetanus. Here I have used as much as eight grammes with a good result. In the case of drunkards, however, I would recommend caution. It is also most advisable not to allow milk to be taken, as was done in the Balham case, since under its use the formation of chloroform goes on rapidly, and may occur in the stomach.

That exceptionally large doses of chloral may be taken by men is proved by the injection of chloral into the veins. An injection of 6.75 grammes of chloral produced in eleven minutes complete auæsthesia, and a sleep which lasted thirteen hours. I merely mention this fact, without entering on a criticism of the treatment.

From what has been adduced, it is evident that the first thing to be ascertained in any unfortunate case is whether the result is due to the chloral or to some otber product accompanying it. According to my view all physicians should take especial care to use only pure crystals, or solutions regarding which there is good ground for trusting to the goodness of the material used by the manufacturers. When this is done it will be possible to speak of a sufficient dose, and to weigh equally the advantages and disadvantages of chloral against each other. 
In my opinion coincident circumstances probably cooperated in the Balbam case; they should not be overlooked, and, considering the novelty of the remedy, and the employment of a preparation recently brought into use for the first time, should not be charged as a subject of blame to the physician.

\section{di altirror}

\section{HOSPITAL PRACTICE,}

\section{BRITISH AND FOREIGN.}

Nulla antem est alia pro certo noscendi via, nisi quamplurimas et morborum et dissectionum historias, tum aliorum, tum proprias collectas habere, et
fnter se comparare.-Moвgagr I De Sed. et Caus. Morb., lib. iv. Procmium.

\section{LONDON HOSPITAL.}

CASE OF SUSPECTED "DISCHARGING LESION" OF THE HINDER PART OF THE UPPERMOST RIGHT FRONTAL CONVOLUTION-ILLUSTRATION OF FERRIER'S RESEARCHES.

(Under the care of Dr. HugHLINGS JACKSON.)

DuRING his charge of the clinical wards Dr. Hughlings Jackson showed several patients who were subject to convulsions beginning loeally, in some part of one side of the body. With reference to them he urged the great importance of the researches of Hitzig and Ferrier, and drew attention to the statement of Charcot that a French physician, Bravais, had, in 1827, described the clinical varieties of epilepsy or of epileptiform seizures under remark. One case was that of a man who had convulsions usually affecting only the left arm; the convulsion was always preceded by an epigastric sensation, probably the same as, or one allied to, the strange epigastric feeling so often mentioned by patients the subjects of what is usually called "genuine" epilepsy as a warning of their seizures. Besides the limitation of nearly all the seizures to the arm, there was another very noteworthy peculiarity : according to the patient, the spasm always passed down the arm. This is a credible thing; Dr. Hughlings Jackson has witnessed such a mode of spreading of spasm in a woman who had very numerous convulsions limited to the right arm. In that woman's case a gliomatous tumour was found affecting the hindermost part of the uppermost frontal convolution, and slightly involving the upper end of the ascending frontal of the side opposite the arm convulsed. The position of disease in this woman's case was correctly predicted from there having been discovered disease of the part named in another case previously under Dr. Hughlings Jackson's care, in which case also the convulsion had been limited to the arm. This was before Ferrier began his important researches, but it is to be observed that this "localisation by disease" closely agrees with one of bis conclusions. Thus, at p. 306 of his recently published "Functions of the Brain," Ferrier writes, when describing a plate of the brain wherein the motor centres are indicated-" (5) Situated at the posterior extremity of the superior frontal convolution, at its junction with the ascending frontal, is the centre for the extension forwards of the arm and hand, as in putting forth the hand to touch something in front."

Considering this woman's case, another essentially similar case also alluded to above, and some facts of a case less conclusive, and more especially the very definite results of Ferrier's experiments, Dr. Hughlings Jackson ventures, in the case of the man recently in the clinical wards, on the diagnosis of a "discharging lesion" of the hindermost part of the right uppermost frontal convolution. Dr. Ferrier saw this patient with Dr. Hughlings Jackson, and agreed with him in the above diagnosis.

This patient has a very curious feeling in his paroxysms, which Dr. Hughlings Jackson has never before heard of in a case of convulsion of any kind. The patient said that during the fit his hand seemed to get gradually up to his shoulder, and at length seemed to be buried in his chest. This is worthy of mention, on account of the somewhat similar feeling of some of those who have undergone amputation of a limb; the "spectral" hand or foot, in course of months or years, gets gradually nearer and nearer to the shoulder or hip.

What kind of disease there may be which is the cause of the "discharging lesion," Dr. Hughlings Jackson does not venture to say; there is no evidence of tumour, unless the limitation of the spasm is some empirical evidence of it.

Remarks on discharging lesions, by Dr. HugHLINGS $\mathrm{J}_{\mathrm{ACK}}$. son.-A "discharging lesion" is an abnormal physiological state; there is local instability of grey matter. The diffculty here, as in most cases of epilepsy and epileptiform seizures, is to ascertain the pathology - that is to say, the nature of the local abnormal nutritive process by which the local instability results.

Dr. Hughlings Jackson continually insists on the neces sity of making a distinction between the abnormal physiological condition (the morbid alteration of the function of nerve-tissue) and the abnormal nutritive process (pathology) by which the abnormal physiological condition is brought about. The term "disease" is frequently used for both or either; no analysis being attempted. The distinction is most easily shown in cases of paralysis. Paralysig points only to the abnormal physiological condition of loss of function of nerve-tissue, and of ten to actual destruction of nerve-tissue; it tells us nothing whatever as to the nature of the pathological process by which that loss of function results. Similarly, convulsion (as also choreal movements, tetanus, \&c.) points only to the abnormal physiological condition of over-function (not better function), or, in other words, to a "discharging lesion," constituted by unstable cells; but convulsion tells us nothing as to the pathological process by which that condition of over-function results It will be observed that Dr. Hughlings Jackson uses the term "functional" simply to describe what is commonly agreed upon to be the function of nerve-tissue, and not for slightness of charge, nor for cases in which recovery quickly follows; there are in this sense of the word only two kinds of functional changes-those of loss of function, and those of over-function. Speaking now only of over-function from morbidly increased instability of nerve-celle, we must go so far as to say that there is increased nutrition; for increased expenditure of energy of necessity implies increased "ab. sorption" of energy-that is, increase of the nutritive process. The difficult question is, "How is this local increase of nutrition determined?" Even when we discover a tumour we have this problem to consider. A tumour is found, let us say, in the uppermost frontal convolution, close upon the ascending frontal; there were frequent convulsions of the opposite arm during life. Now the tumour cannot discharge; the discharge is of grey matter, and, as Dr. Hughlings Jackson supposes, of grey matter round about the tumour. But whether this be so, or whether the discharge be, as many would believe, of the medulla oblongata, the difficult question is, By what process did the tumour lead to instability of cells permitting occasional excessive discharge, be those unstable cells where they may?

Thanks to Hitzig and Ferrier's researches, the locality of "discharging lesions" is, Dr. Hughlings Jackson thinks, a matter on which physicians have been wonderfully and unexpectedly assisted. But a great void remains to be filled with regard to the pathological process by which discharging lesions result. But even here it is probable that Ferrier's researches will help us. For particular patho. logical processes affect, so to speak, particular seats. And in this regard the researches of Duret on the distribution of cerebral arteries ought to be very carefully considered Dr. Hughlings Jackson's speculation is that in most cases where there is found no tumour as a cause of convulsion the "discharging lesion" is the result of embolism or thrombosis of arteries.

\section{VICTORIA HOSPITAL FOR CHILDREN, CHELSEA.}

\section{ABDOMINAL CYSTIC TUMOUR; REPEATEDLY TAPPED ;}

INJECTION OF A WEAK SOLUTION OF IODINE; RAPID RECOVERY.

(Under the care of Dr. Griga and Mr. Cowelu.)

For the following interesting notes we are indebted to Mr. R. Walford, house-surgeon.

William J-C, aged four years, was admitted on May 25th, 1876. He was well nourished, but rather pale, and had 